\title{
The MAP Kinases are Differently Utilized by CD28 and CD2 Adhesion Pathways in Superantigen-Activated Jurkat T cells
}

\author{
EDWARD VISSE ${ }^{2}$, JUAN INOSTROZA ${ }^{1}$, GERTRUDIS CABELLO $^{3}$, \\ and EDUARDO PARRA ${ }^{1}$
}

\begin{abstract}
${ }^{1}$ Instituto de Ciencias Biomedicas, Facultad de Medicina, Universidad de Chile, Independencia 1027. Casilla 70000-Santiago 7, CHILE, ${ }^{2}$ Glioma Immuno Therapy group. Biomedical Center (BMC) B11 University of Lund, 22184 Lund, SWEDEN, ${ }^{3}$ Departamento de Biología y Salud. Facultad de Ciencias, Universidad de Tarapacá, Arica. Velásquez 1775 Arica, CHILE.
\end{abstract}

\begin{abstract}
To mimic the two-signal requirements for $\mathrm{T}$ cell activation mediated by ligands, we exposed the superantigens SEA or SEE (signal 1) to T cells incubated with HLA-DR/LFA-3 or HLA-DR/B7-1-CHO transfected cells (signal 2). LFA-3 costimulation was able to induce T cell proliferation as well as IFN- $\gamma$ and IL-4 production at similar levels as in cells induced by B7-1. Analysis of the CD28RE of the IL-2 promoter showed specific transcription factor recruitment at the CD28RE element upon induction by B7-1/SEE. Further functional studies with an IL-2 enhancer-promoter carrying either wild type or mutated versions of the CD28RE site revealed that this element is necessary for full activation upon B7-1 costimulation. While both CD28/B7-1 and CD2/LFA-3 costimulation resulted in the up-regulation of IL-4 and IFN- $\gamma$ promoters, IL-2 promoter activity and production of IL-2 were only seen after B7-1 costimulation. However, contrary to what has been previously proposed, we show that costimulation with either B7-1 or LFA-3 further enhanced the ERK-2 activity and strongly activated the p38 MAPK pathway, but only B7-1 costimulation induced high levels of JNK-1 activity. These data suggest that the differential effect of CD28 vs. CD2 can be related to the difference in the ability of the two pathways to induce JNK-1 activity.
\end{abstract}

Key terms: CD28 response element; Staphylococcal Enterotoxin A-E; Extracellular signal regulated kinase; c-Jun N-terminal kinase; Interleukin-2.

\section{INTRODUCTION}

In addition to $\mathrm{T}$ cell receptor (TCR) crosslinking (signal one), optimal $\mathrm{T}$ cell activation requires engagement of the costimulatory molecule CD28 by its ligand B7-1 (CD80) on Antigen presenting cells (APC) (signal two) (Parra et al., 1994; Schwartz 1992; Linsley et al., 1991; Faroudi et al., 2002; Parra, 2002). The ligand for CD28 is B7 (B7-1/CD80 and B7-2/CD86), which displays a restricted pattern of expression on APCs, including activated $\mathrm{B}$ cells, suggesting an important role for CD28 in the interaction between $\mathrm{T}$ and $\mathrm{B}$ cells (Freeman et al., 1989; Linsley et al.,
1990; Lenschow et al., 1996; Van Seventer et al., 1991). Furthermore, CD28 costimulation synergizes with TCR signals to increase IL-2 production and $\mathrm{T}$-cell proliferation in a cyclosporine A-insensitive manner (Mattila et al., 1990; Williams et al., 1992).

Another receptor on $\mathrm{T}$ cells that can induce the secondary stimulus required for $\mathrm{T}$ cell activation is the CD2 receptor, which recognizes and binds its ligand on the surface of the antigen presenting cells (Bierer et al., 1988; 1989; Janeway and Golstein, 1993). Like CD28, CD2 has a relatively large and highly conserved cytoplasmic domain, which allows

Corresponding author: Eduardo Parra, Ph.D. (Med. Sci), Laboratorio of Signal Transduction and Gene Therapy, Disciplinary Program of Pharmacology, ICBM, Faculty of Medicine, University of Chile, Av. Independencia 1027, Santiago, Chile. Telephone: (56-2) 678-6654 - Fax: (56-2) 737-2783. E-mail: eparra@machi.med.uchile.cl 
association with the Src-like kinases, Fyn and Lck (Rabb et al., 1995; Schneider et al., 1995). Despite that CD2 ligation may also transduce an independent signal, initiating T cell activation (Kabelit et al., 1990), it seems that a major role for CD2 molecules is to enhance the TCR/CD3-or CD28 mediated response, particularly in resting and naive $\mathrm{T}$ cells (Bierer et al., 1989; Kabelit et al., 1990). LFA-3, the natural human ligand for CD2, is a glycoprotein expressed on virtually all nucleated cells. It is also a member of the Ig super gene family. Several lines of evidence have demonstrated that CD2 binds to its ligand LFA-3 with high affinity and thus should play a significant role in stabilizing initial cell-cell interactions and adhesion prior to the TCR/MHC class II+complex interaction (Shaw et al., 1988; Springer et al., 1987; Springer, 1990).

The induction of signals one and two in $\mathrm{T}$ cells leads to the activation of several signal transduction pathways, including the MAP kinase family of enzymes (Nunes et al., 1996; Zhang et al., 1999). These enzymes play a critical role in a diverse number of signal transduction pathways in response to mitogenic stimuli, and they are directly implicated in the linking of cytoplasmic signaling cascades to the control of transcription in the nucleus (Robinson et al., 1996). The MAPK family is divided into two main groups. The Extra cellularly Regulated Kinases (ERK group) (Boulton et al., 1991) and the StressActivated Protein kinase (SAPK group), which includes the c-Jun N-terminal Kinase (JNK) and p38 kinase (Hibi et al., 1993; Minden et al., 1994). Dual phosphorylation of these kinases on a TXY motif in their activation loop results in an open, catalytically active, conformation. The active kinases phosphorylate several transcription factors, including Elk-1, cJun, and ATF-2, which are involved in the regulation of c-fos and c-jun gene expression (Gille et al., 1992; Minden et al., 1995; Gupta et al., 1995; Karin, 1995). Several reports using other models, have shown the importance of the MAP kinases for cell proliferation (Leiva-Salcedo et al., 2002). The activation of c-Jun and c-Fos proteins form a complex called "Activator protein-1" (AP-1) which was first identified as a transcriptional factor that binds to an essential cis-element of the human metallothionine IIa (hMTIIa) promoter (Lee et al., 1987; Gille et al., 1992; Davis et al., 1994; Nebreda et al., 1994). Later the binding site for AP-1 was also recognized as the TPA response element (TRE) of several cellular and viral genes including human collagenase, SV40 and IL-2. Indeed, the AP1 complex plays a critical role in controlling IL-2 gene transcription (Angel et al., 1987; 1991; Steal et al., 1991), by binding to three sites: the NF-AT, Oct-1, and AP-1 itself. The expression of the IL-2 gene is regulated by its $5^{\prime}$ - flanking promoter sequence and its critical regulatory and inducible activity is contained within the $300-\mathrm{bp}$ region immediately upstream of the start site (Parra et al., 1997; Rahmsdorf et al., 1990; Durand et al., 1988; Granelli-Piperno et al., 1991). The IL-2 promoter includes defined binding sites for the transcription factors NF-AT, NF- $\kappa$ B, AP-1, Oct-1, and CD28RC (Parra et al., 1997; Jain et al., 1992a, 1992b). Thus, activated $\mathrm{T}$ cells produce IL-2, express high affinity IL- 2 receptors, and proliferate in an autocrine or paracrine fashion. However, the interaction of the CD28 and B7-1 molecules has been recognized as the major pathway in the regulation of IL-2 expression, and subsequently several reports have demonstrated its specificity to this respect (Parra et al., 1993; Fraser et al., 1991; Fraser and Weiss 1992). Early reports showed that CD3 cross-linking by antibodies could induce ERK-2 activity and that antibodies against CD28 failed to increase the activity of ERK-2 in Jurkat T cells (Minden et al., 1994; Steal et al., 1991). However, one major discrepancy of this study compared with others was that we could strongly increase the ERK-2 activity after TCR and LFA-3 or CD28 costimulation. This discrepancy may reflect differences in the use of CD3 and CD28 antibodies v/s a superantigen and B7-1 costimulatory molecule expressed in CHO-DR cells. A role for the JNK and ERK cascades in $\mathrm{T}$ cell activation has been described, but the links between receptor engagement and downstream events still need to be defined. 
MATERIALS AND METHODS

\section{Reagents}

Staphylococcal enterotoxins A and E (SEA, SEE) were purchased from Toxin Technology (Madsion, W I). Ficollisopaque, G418 and L-methionine sulfoximine (MSX) were purchased from Pharmacia Inc. (Uppsala, Sweden). The protease inhibitors phenylmethylsulfonyl fluoride (PMSF), leupeptin, pepstatin, aprotinin and bestatin were from Roche, USA. $\left[\gamma^{32}\right.$ P]ATP was from Amersham. T4 polynucleotide kinase and poly $(\mathrm{dI}-\mathrm{dC})_{2}$, were obtained from Amersham Pharmacia Biotech (Piscataway, NJ). Tris-BorateEDTA buffer and acrylamide-bisacrylamide (29:1) were obtained from Bio-Rad (Richmond, CA). PHAS-1 was purchase from Strategene (La Jolla, CA). Luciferase assay reagent, lysis buffer and the pGL-2 luciferase vector were obtained from Promega (Madison, WI). Recombinants and mAbs to human IL-2 (5344.111 and B33-2), IL-4 (8D4-8, MP4-25D2) and IFN- $\gamma$ (NIB42, 4S.B3) were obtained from PharMingen (San Diego, CA). Phorbol-12Myristate-13-Acetate (PMA) and Ionomycin were purchased from ICN Pharmaceuticals (Costa Mesa, CA). GSTcJun, GST-ATF-2 were a gift from Dr. Roger J. Davis (Howard Hughes Medical Institute, MA). Production and purification of GST-cJun and GST-ATF-2 proteins were performed as described (Hibi et al., 1993).

\section{Cell separation, culture and stimulation}

Peripheral blood lymphocyte (PBL) were isolated from buffy coats obtained from healthy blood donors by density centrifugation over Ficoll-Paque (Pharmacia Biotech, Uppsala Sweden) as previously described (Parra et al., 1995). T cells were enriched by separation over a gelatin column followed by positive selection of $\mathrm{CD}^{+} \mathrm{T}$ cells by MACS (Miltenyi Biotech, Sunnyvale, CA) according to the manufacturer's description. The purity of the separated cells was routinely checked by FACS analyses and was $99 \% \mathrm{CD}^{+}$cells.

The purified $\mathrm{CD}^{+} \mathrm{T}$ cells were resuspended in RPMI 1640 supplemented with $2 \mathrm{mM}$ glutamine and 10\% FCS. The cells were stimulated with $10 \mathrm{ng} / \mathrm{ml}$ SEA presented by $\mathrm{CHO}$ transfectants at a $\mathrm{T}: \mathrm{CHO}$ ratio of 20:1. After $72 \mathrm{~h}$, the cultures were pulsed with $0.5 \mu \mathrm{Ci}\left[{ }^{3} \mathrm{H}\right]$ thymidine and harvested after an additional $4 \mathrm{~h}$. The amount of incorporated $\left[{ }^{3} \mathrm{H}\right]$ thymidine was determined by liquid scintillation counting. The human $\mathrm{T}$ leukemia cell line Jurkat was maintained at logarithmic growth in RPMI 1640 supplemented with $2 \mathrm{mM}$ glutamine and $10 \%$ fetal calf serum. The transfected $\mathrm{CHO}$ cells were maintained in the same medium with G418 and/or MSX. Stimulation of the $\mathrm{T}$ cells with SEE was done at a concentration of $1 \times 10^{6}$ cells $/ \mathrm{ml}$ in the presence of $0.1 \times 10^{6}$ cells $/ \mathrm{ml} \mathrm{CHO}$ cell transfectants at $37{ }^{\circ} \mathrm{C}$ as previously described (Parra et al., 1994; 1995).

\section{Transfected cell lines}

CHO cells stably transfected with the cDNAs encoding the human HLA-DR, B7-1 and LFA-3 cell surface molecules have been described in detail elsewhere (Parra et al. 1995). Single and double transfectants expressing similar levels of the transfected molecules were established by repeated cell sorting and they were periodically reanalyzed.

\section{Plasmids}

The human IL-2 promoter-enhancer fragment (Durand et al. 1988; GranelliPiperno et al., 1991), nucleotides -500 to +60 , was subcloned from pSV-IL-2-CAT into the luciferase reporter vector pGL2 (Promega, Madison, WI). The -500-to +60 fragment was prepared by PCR with appropriate primers creating a $5^{\prime}-$ XhoI site and a $3^{\prime}$-HindIII restriction sites. The IL-2 promoter mutated in the CD28RE region was generated by PCR directed splicing overlap extension, to replace positions -159 to -164 with the sequence $5^{\prime}$-CCTCGA-3'. Constructs were confirmed by sequencing. 


\section{Preparation of nuclear extracts}

Human Jurkat leukemia CD4 T cells (3-5 x 107 cells) were stimulated with various irradiated transfected $\mathrm{CHO}$ cells $(8000 \mathrm{rad})$ in the absence or presence of SEE (100 ng/ $\mathrm{ml}$ ) at $37^{\circ} \mathrm{C}$ (in a humidified atmosphere containing $5 \% \mathrm{CO} 2)$. The cells were harvested after $6 \mathrm{hr}$ of culture and T cells were separated from $\mathrm{CHO}$ cells using a plastic adherence technique. The harvested $\mathrm{T}$ cells were re-suspended in $10 \mathrm{ml}$ PBS and pelleted by centrifugation for $5 \mathrm{~min}$ at 1500 rpm. The pellet was resuspended in $1 \mathrm{ml}$ PBS, transferred into an Eppendorf tube and repelleted by spinning for $15 \mathrm{sec}$ in a microfuge. PBS was removed and the cell pellet was re-suspended in $500 \mu \mathrm{l}$ cold buffer A (10 mM Hepes $\mathrm{pH} 7.8 ; 15 \mathrm{mM}$ $\mathrm{KCl} ; \mathrm{MgCl} 2$ 2mM; $0.1 \mathrm{mM}$ EDTA; $1 \mathrm{mM}$ DTT; $1 \mathrm{mM}$ PMSF). T cells were allowed to swell on ice for $15 \mathrm{~min}, 25 \mu \mathrm{l}$ of a $10 \%$ solution of NP-40 was added, and the tube was vortexed vigorously for $10 \mathrm{sec}$. The homogenate was centrifuged and the nuclear pellet was re-suspended in $100 \mu \mathrm{l}$ ice-cold buffer B (20 mM HEPES pH 7.9; $0.4 \mathrm{M} \mathrm{NaCl} ; 1 \mathrm{mM}$ EDTA; 1mM EGTA; $1 \mathrm{mM}$ DTT; $1 \mathrm{mM}$ PMSF) and the tube was rocked for $15 \mathrm{~min}$ at $4^{\circ} \mathrm{C}$ on a shaking platform. The nuclear extract was centrifuged for $5 \mathrm{~min}$ at $4{ }^{\circ} \mathrm{C}$ and the supernatant was frozen in aliquots at $-70^{\circ} \mathrm{C}$. Before use of the buffers $\mathrm{A}$ and $\mathrm{C}$, a mixture of the protease inhibitors was added: $0.5 \mu \mathrm{g}$ Leupeptin $/ \mathrm{ml} ; 0.7 \mu \mathrm{g}$ Pepstatin/ml; $1 \mu \mathrm{g}$ Aprotinin $/ \mathrm{ml}$ and $40 \mu \mathrm{g}$ Bestatin $/ \mathrm{ml}$. 1-2 $\mu$ l of the nuclear extract (2-4 $\mu \mathrm{g}$ protein) was used for a gel shift assay in the presence of $3 \mu \mathrm{g}$ poly $\mathrm{dI}-\mathrm{dC}$ as previously described (Parra et al., 1997).

\section{Electrophoretic mobility shift assay (EMSA).}

The double-stranded oligonucleotides corresponding to the wild type, mutated CD28RE of the IL-2 promoter were (coding strand): 5'-CTCAAGATCGAAATTCCAAAGAGAC-3', and 5'-CTCAAGATCGACCTCGAAAAGAGAC-3', respectively (the mutation is underlined). One to $2 \mu \mathrm{l}$ of nuclear extract corresponding to $5-10 \mu \mathrm{g}$ of protein were added to $4 \mu \mathrm{l}$ binding buffer containing 2 to $3 \mu \mathrm{g}$ poly (dI-dC) 2 as a non-specific competitor. The reaction mixtures were incubated at $37^{\circ} \mathrm{C}$ for $30 \mathrm{~min}$ with $15,000 \mathrm{cpm}$ of double-stranded ${ }^{32} \mathrm{P}$ labeled oligonucleotides in a final volume of $15 \mu \mathrm{l}$. The samples were electrophoresed on $5 \%$ polyacrylamide gels in $89 \mathrm{mM}$ Tris, $89 \mathrm{mM}$ boric acid, $2 \mathrm{mM}$ EDTA. The gels were fixed in $40 \%$ methanol and $10 \%$ acetic acid for $15 \mathrm{~min}$, dried, and visualized by autoradiography (Parra et al., 1997).

\section{DNA transfection and Luciferase activity} assay.

Transfection of Jurkat cells was carried out by electroporation. Briefly, plasmid DNA was mixed with exponentially growing Jurkat cells $\left(20 \times 10^{6}\right.$ cells $\left./ \mathrm{ml}\right)$ in complete medium and the cells were electroporated in an electro cell manipulator 600 (BTX, San Diego, CA.) using $130 \mathrm{~V} / 1700 \mu \mathrm{F}$ capacitance. The transfected cells were cultured for $24 \mathrm{hrs}$ before being stimulated with the different CHO-transfected cell lines with or without $100 \mathrm{ng}$ SEE/ml. After various periods of time, cells from each independent well were harvested, washed twice in PBS and treated with lysis buffer (Luciferase Assay Promega, Madison, WI) for 5-10 $\mathrm{min}$ on ice. Lysates were spun down for $1 \mathrm{~min}$ and the total supernatants were analyzed using Luciferase Reagent (Promega) and measured as a duplicate in a luminometer (MicroLumat LB $96 \mathrm{P}$, Berthold) for $5 \mathrm{~s}$. Background measurement was substracted from each duplicate and experimental values are expressed either as recorded light units, Luciferase activity or as relative activity compared to extracts from unstimulated cells.

\section{JNK/ERK/p38 Kinase Activity Assays}

Jurkat $\mathrm{T}$ cells were incubated with or without SEE and the different $\mathrm{CHO}$ cells (CHO-DR, CHO-DR/B7-1 and CHO-DRLFA-3) for 30, 60, and 120 minutes (for ERK-2 and JNK-1) or 60, 120, and $180 \mathrm{~min}$ (for $\mathrm{p} 38$ ). After time periods the $\mathrm{CHO}$ cells were removed by plastic adherence and the Jurkat $\mathrm{T}$ cells were collected and lysed, and 
the proteins of interest were immune precipitated using $\mathrm{mAb}$ to JNK-1 (Santa Cruz), ERK-2 and p38 and protein Asepharose CL-4B beads for 3 to $4 \mathrm{~h}$. Beads were washed 3 times with lysis buffer, twice with $\mathrm{LiCi}$ and twice with kinase buffer (25 mM HEPES, pH 7.4, $25 \mathrm{mM}$ glycerophosphate, $25 \mathrm{mM} \mathrm{MgCl} 2,25 \mathrm{mM}$ DTT, and $0.1 \mathrm{mM} \mathrm{Na} \mathrm{VO}_{4}$ ), and finally resuspended in $30 \mu \mathrm{l}$ of kinase buffer. The beads were then incubated with human GST-c-Jun (1-79) for JNK-1, GST-ATF-2 (1-109) for p38, PHAS-I (Strategene, La Jolla, CA) for ERK-2, and $1 \mu \mathrm{l}$ of $[\gamma-$ $\left.{ }^{32} \mathrm{P}\right] \mathrm{ATP}$ at $30^{\circ} \mathrm{C}$ for $30 \mathrm{~min}$. One volume of $2 x$ sample buffer (125 mM Tris, 6\% SDS, $20 \%$ glycerol) was added, and the reaction mixtures were boiled at $100^{\circ} \mathrm{C}$ for $3 \mathrm{~min}$. Phosphorylated proteins were analyzed by SDS-PAGE and autoradiography.

\section{Cytokine assays}

Cytokine levels in supernatants of unstimulated and stimulated $\mathrm{T}$ cells were determined by specific ELISAs using a sandwich technique as previously described (Sundstedt et al., 1997) and according to the manufacturer. Recombinant cytokines used for standard curves in ELISA and specific $\mathrm{Ab}$ pairs for each cytokine were obtained from PharMingen (San Diego, CA); IL-2 (5344.111 and B33-2), IL-4 (8D4-8, MP425D2) and IFN- $\gamma$ (NIB42, 4S.B3).

\section{RESULTS}

B7-1 and LFA-3 costimulation in Jurkat cells induces distinct protein binding complexes that recognize the CD28RE sequence contained in the IL-2 promoter.

We first investigated the relative role of B7-1 and LFA-3 on the transcriptional regulation of the IL-2 promoter. The minimal inducible IL-2 enhancer region has been identified as a $300 \mathrm{bp}$ region upstream of the transcription start site. A number of target sites recognized by various transcription factors have been identified within this region, including the CD28RE, AP-1, NF-AT and NF- $\kappa$ B (Jain et al., 1992a;
Parra et al., 1993). However, mutational analyses has demonstrated that the CD28RE plays a crucial role in the transcriptional activation of the IL-2 promoter.

Electrophoretic mobility shift assay (EMSA) was used with nuclear extracts prepared from costimulated Jurkat $\mathrm{T}$ cells and oligonucleotides encoding the wild type radiolabeled CD28RE of the IL-2 promoter to analyze the protein complexes that recognize this sequence. Figure 1 shows that costimulation with SEE and B7-1 or LFA-3 induces distinct nuclear factor or binding protein complexes which strongly bind to the CD28RE sequence (Fig.1A). Unstimulated and HLA-DR stimulated Jurkat cells did not contain detectable levels of nuclear factors (Fig. 1A). No binding was detected in Jurkat cells presented with HLA-DR either nonstimulated or treated with SEE. However, when cells were costimulated with B7-1 or LFA-3, strong protein binding complexes were detected, which were differently activated by both receptor pathways. These protein-DNA complexes were not competed with cold Oct-1 specific oligonucleotide, suggesting that the Oct-1 transcription factor is not present in these complexes. As a control, we stimulated Jurkat cells (not presented with $\mathrm{CHO}$ transfectants) with SEE or PMA/Ionomycin. As observed with the CHO transfectants, SEE alone did not induce any specific protein binding complex. However, PMA/I induced a strong complex with a higher electrophoretic mobility than that observed with B7-1/ LFA-3 costimulation. When the same extracts were incubated with a mutated CD28RE sequence, the DNA-protein binding activity was completely abolished (Fig 1B). Only a residual binding activity was observed in Jurkat cells stimulated with PMA/Ionomycin.

Strong costimulatory effect of B7-1 and LFA-3 on transcriptional induction of $I L-2$ promoter activity by B7-1 and LFA-3 required a functionally intact CD28RE.

The functional importance of the CD28 response element was further dissected comparing the transcriptional response of transiently transfected Jurkat $T$ cells with a 

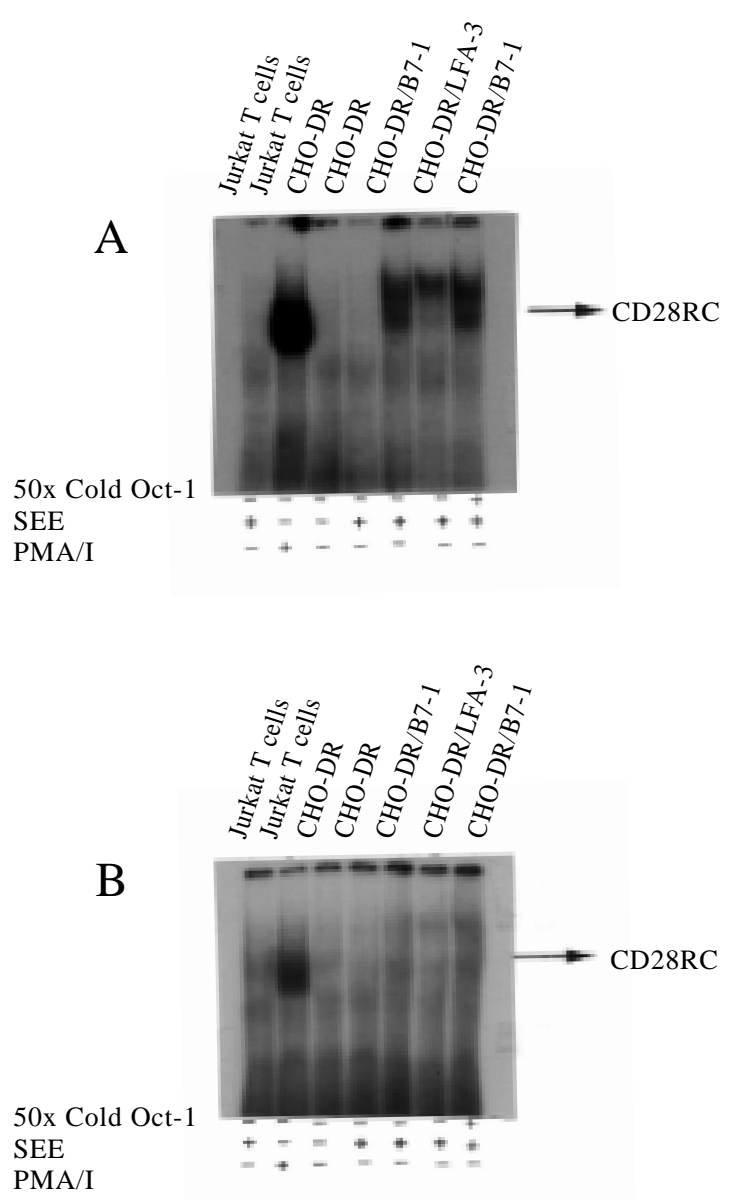

\section{Figure 1}

Jurkat $\mathrm{T}$ cells were incubated in RPMI supplemented with $10 \%$ FBS. The cells were the stimulated with the various indicated $\mathrm{CHO}$ transfectants for $6 \mathrm{~h}$, in the presence or absence of SEE $100 \mathrm{ng} / \mathrm{ml}$, or with PMA/Ionomycin as a positive control. Nuclear cell extracts were prepared and analyzed by EMSA.

In $\mathrm{A}$, protein binding to the CD28RE of the IL2 promoter using a oligonucleotide corresponding to the 5'-CTCAAGATCGAAATTCCAAAGAGAC-3', of the IL-2 promoter. In B, the mutated version of the IL-2 promoter sequence showed above. 5'-CTCAAGATCGACCTCGAAAAGAGAC-3'. Sequence specificity of the CD28RE was assessed by incubating nuclear extract with radiolabeled CD28RE oligonucleotides in the presence of no competitor Oct-1 at 50-fold molar excess (5'CGTCTCATGCGATGCAAATCACTTGAGATC $3^{\prime}$ ). The mutation is showed in bold face. The results from one of two similar experiments are shown. luciferase reporter-construct carrying the wild type IL-2 and the mutated version of this CD28RE. As we previously reported (Parra et al., 1997), a strong induction of the IL-2 promoter activity was observed by costimulation of Jurkat $T$ cells with SEE and B7-1, but not with SEE and LFA-3 (Fig. 2). Importantly, this activity was severely reduced in the IL-2 promoter carrying a mutation in the CD28RE. We showed that the transcriptional activity of an IL-2 promoter reporter construct carrying a mutated version of the CD28RE was strongly reduced in B7-1 costimulated Jurkat $\mathrm{T}$ cells compared to the wild type (Fig. 2). These results further support a major role of the CD28/B7-1 pathway in the induction of IL- 2 and $\mathrm{T}$ cell activation.

Requirement of both signals for an optimal induction of JNK-1, ERK-2, and p38 kinases activities.

To examine whether SEE (signal one) alone or together with LFA-3 or B7-1 (signals two) costimulation can activate the mammalian JNK-1, ERK-2 and p38 kinase cascades, we activated Jurkat $\mathrm{T}$ cells with and without SEE and costimulated with CHO-DR, CHO-DR/B 7-1, or CHO-DRLFA-3 for given periods of time.

JNK-1 was immunoprecipitated from the lysates (using a specific antibody, JNK1 (C17): sc-474, Santa Cruz Biotechnology, Inc.) kinase assay with GST-c-Jun, (amino acids 1-79) as protein substrate (Fig. 3). We show that optimal induction of JNK-1 activity required the participation of both signals, since SEE alone did not affect basal levels of the kinase activity. Substantial activation of JNK-1 was already observed after $30 \mathrm{~min}$ of costimulation. This activity peaked around 60 min after B7-1 costimulation and decreased after $120 \mathrm{~min}$ (Fig. 3C).

To determine whether SEE (signal one) and LFA-3 (signal two) costimulation could also activate the mammalian ERK-2 and p38 pathways, similar assays were employed. ERK-2 and p38 were immunoprecipitated and their activities were determined by phosphorylation of either PHAS-1 protein or GST-ATF-2 respectively. As reported previously, ERK- 


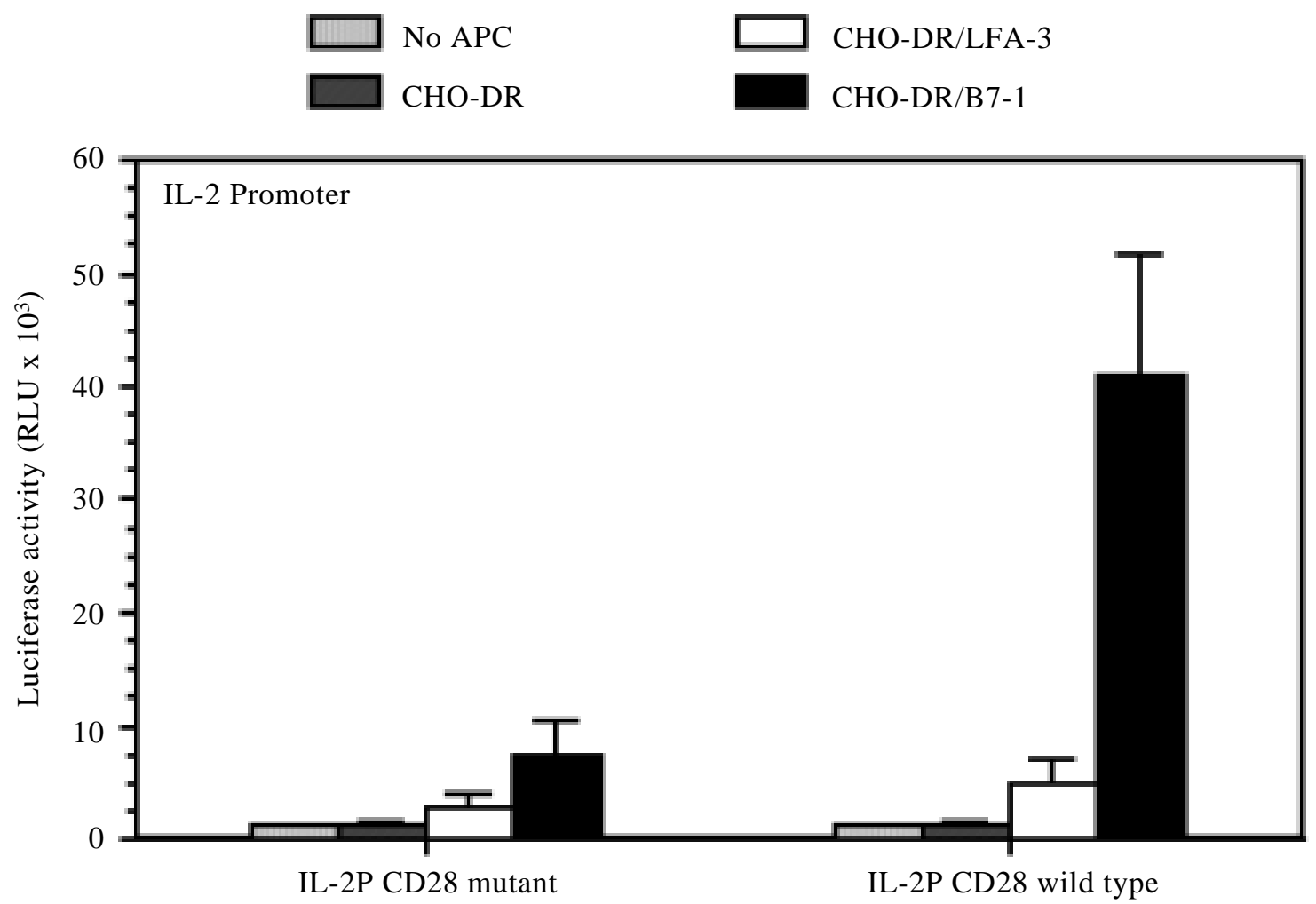

\section{Figure 2}

Functional demonstration of the specificity of the CD28RE in the transcriptional activity of a wild type and a mutated version of the IL-2 promoter. Jurkat T cells were transfected with the wild type IL-2 luciferase reporter gene or with the mutant version. After $24 \mathrm{~h}$ incubation the cells were stimulated with SEE and the CHO and CHO transfectants CHO-DR, CHO-DR/LFA-3 and CHODR/B7-1. Eight hours later, samples were harvested and analyzed for luciferase activity. The native CD28RE sequence of the IL-2 promoter 5'-AAATTC-3' was mutated to the 5'-CCTCGA-3' sequence (mutation shown in bold-face). Luciferase activity is expressed as arbitrary light units minus background units of buffer alone. Results from one of two similar experiments are shown.

2 activity was elevated $30 \mathrm{~min}$ of costimulation with signal one (CHO-DR/ SEE) (Fig. 4A). However, in our system, LFA-3 and B7-1 costimulation (signal two) increased the activity of ERK-2 several fold, suggesting a principal role for signal two in the up-regulation of ERK-2 activity. The optimal activity peaked $60 \mathrm{~min}$ after DR, DR/B 7-1 and DR-LFA-3 costimulation (Fig. 4B) and decreased after $120 \mathrm{~min}$ (Fig. 4C). Interestingly, LFA-3 costimulation proved to be more effective than B7-1 in increasing the levels of ERK-2 activity (Fig. 4B and C). These results suggest a synergistic role between TCR and CD2 to superinduce the levels of ERK-2 activity.
We finally investigated the activation of p38 kinase. Similarly to JNK-1, B 7-1 costimulation strongly activated p38 kinase activity in Jurkat T cells (Fig. 5). No p38 kinase activity was detected in the absence of costimulation, suggesting the requirement of both signals to induce p38 activity. However, activation of p38 kinase activity was only observed after $120 \mathrm{~min}$ of costimulation with either B7-1 and or LFA-3 and decreased to basal levels after $180 \mathrm{~min}$ of costimulation (Fig. 5).

Western blot analysis confirmed that JNK-1, ERK-2 and p38 kinases were expressed at comparable levels (data not shown). 

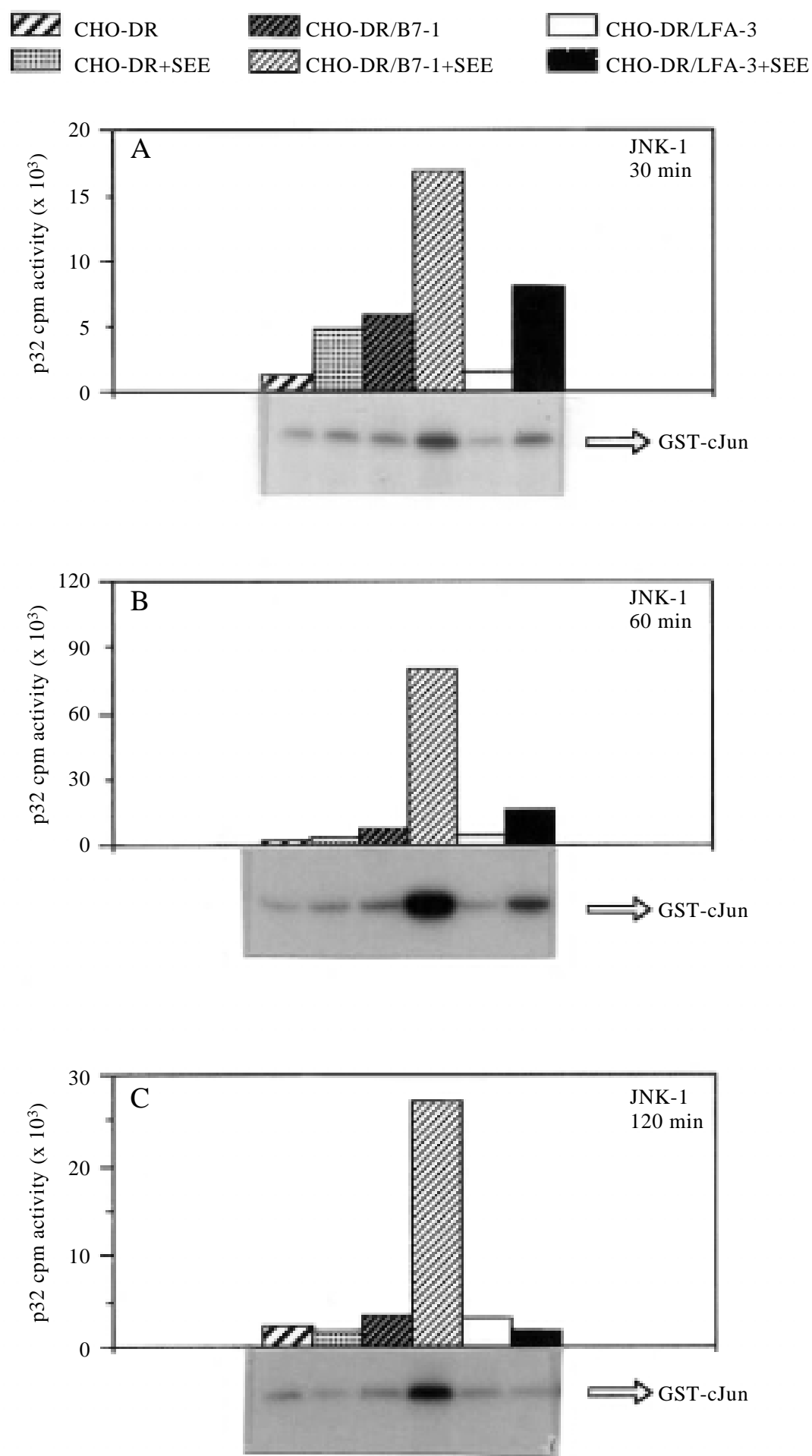

\section{Figure 3}

Activation of the JNK-1 MAP kinase member by SEE (100 ng/ml) and the CHO-DR, CHO-DR/B71 and CHO-DR/LFA-3. Jurkat cells were incubating in medium containing $10 \%$ FBS. The cells were stimulated with and without SEE and the various $\mathrm{CHO}$ transfectants for the indicated periods of time (in minutes). Whole cell extracts were prepared and assayed for JNK-1 using and immune complex kinase assay with GST-c-Jun as substrate. The cpm activity with respect to untreated cells is shown above the kinase assay panel. 

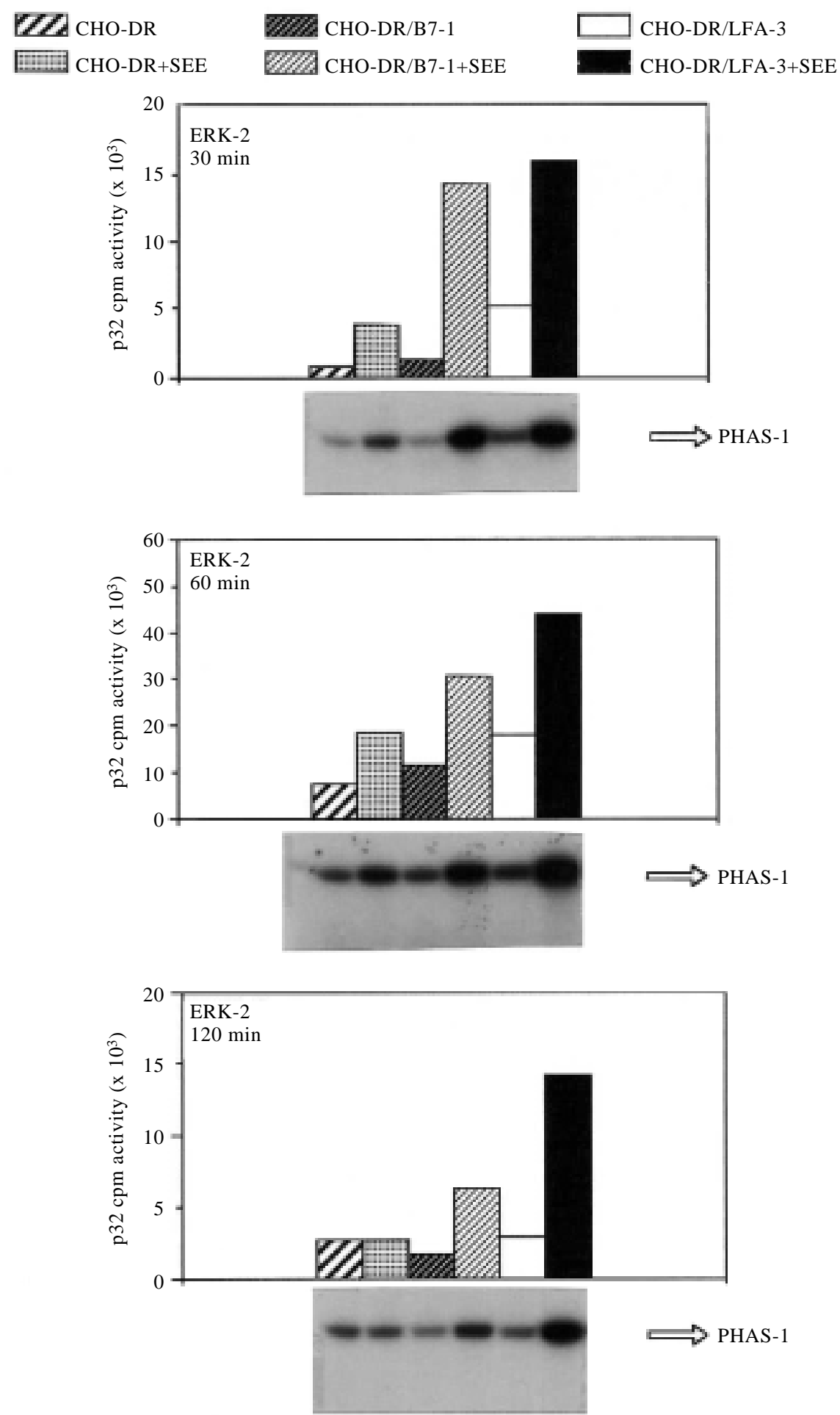

\section{Figure 4}

Activation of the ERK-2 MAP kinase member by SEE (100 ng/ml) and the CHO-DR, CHO-DR/B71 and CHO-DR/LFA-3 in Jurkat T cells stimulated with and without SEE and the various CHO transfectants for the indicated periods of time (in minutes). Whole cell extracts were prepared and assayed for ERK-2 using and immune complex kinase assay with PHAS as substrate. The cpm activity with respect to untreated cells is shown above the kinase assay panel. These experiments were performed at least twice with identical results. A representative experiment is shown. 


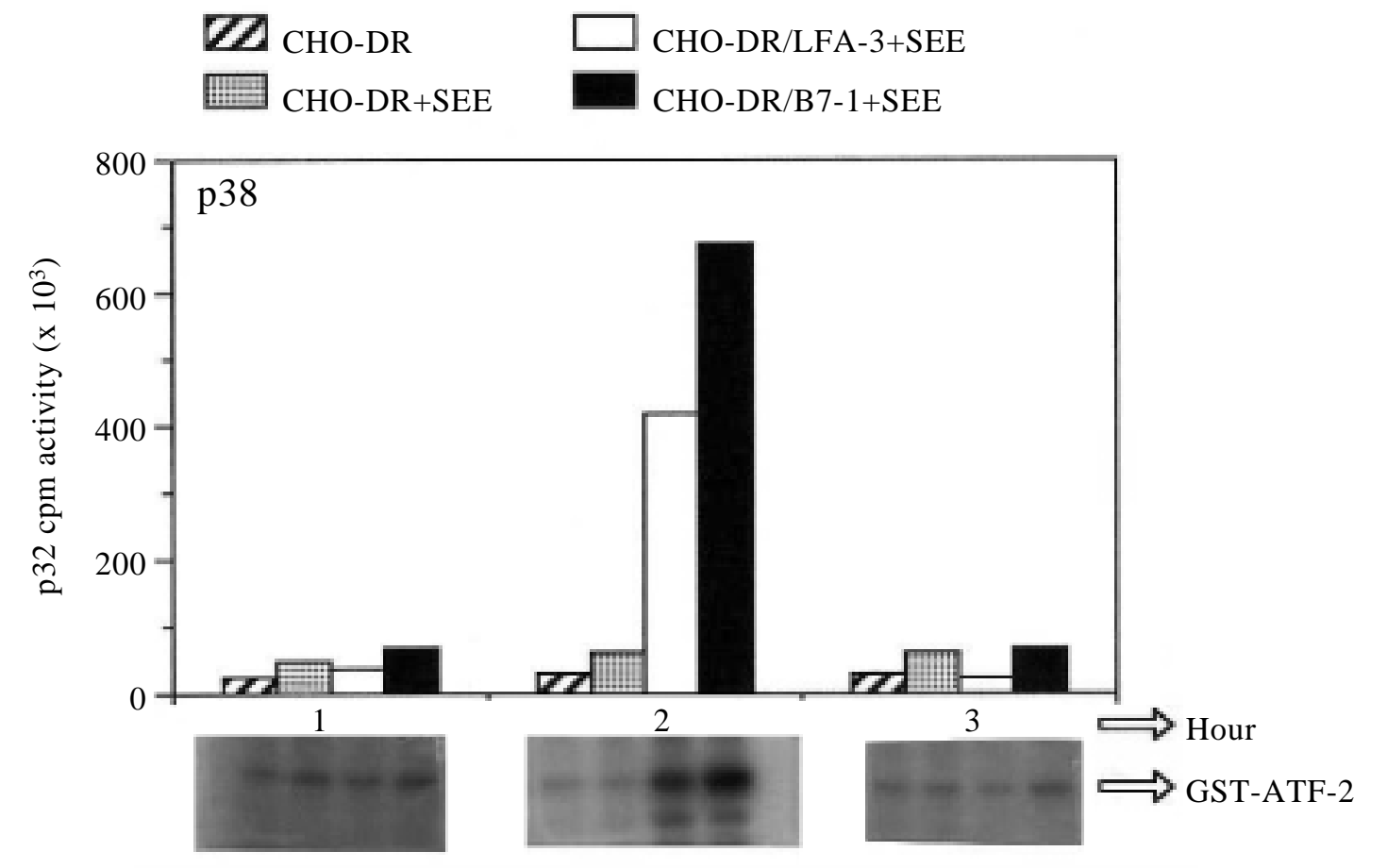

\section{Figure 5}

Activation of the p38 MAP kinase member by SEE (100 ng/ml) and the CHO-DR, CHO-DR/B7-1, CHO-DR/LFA-3 and Jurkat cells were incubating in medium containing 10\% FBS. The cells were stimulated with and without SEE and the various CHO transfectants for the indicated periods of time (in minutes). Whole cell extracts were prepared and assayed for p38 using and immune complex kinase assay with GST-ATF-2 as substrate. The cpm activity with respect to untreated cells is shown above the kinase assay panel.

Costimulation by B7-1 strongly induces the transcriptional activity of the IL-2, INF- $\gamma$ and IL-4 promoters-enhancer region in Jurkat $T$ cells transiently transfected with luciferase reporter constructs.

Based on the role of the CD28/B7-1 pathway in $\mathrm{T}$ cell activation, we wanted to analyze the effects of LFA-3 and B7-1 costimulation on the transcriptional activity of several promoters that play important roles in the immunological response, such as IL-2, IFN- $\gamma$ and IL-4. Jurkat T cells were transiently transfected (electroporation) with the human IL-2 (Fig. 6A) IFN- $\gamma$ (Fig. 6B), and IL-4 (Fig. 6C) promoter regions fused to the luciferase reporter gene. The transfected cells were then stimulated with SEE (100 ng/ $\mathrm{ml}$ ) and presented to the different $\mathrm{CHO}$ transfectants, after which the luciferase activity was measured. As shown in figure 6, stimulation with SEE alone in the absence of signal two did not affect the transcriptional activity of the different promoters (Fig. 6 A, B, and C). Similarly, signal two (B7-1 or LFA-3) had no effect in the absence of SEE. However, costimulation with B7-1 resulted in a very strong transcriptional activation of all three promoters, IL-2, IFN- $\gamma$, and IL-4 (Fig. $6 \mathrm{~A}, \mathrm{~B}$, and $\mathrm{C}$ ). In contrast, costimulation with LFA-3 had no effect on IL-2 transcriptional activity, but it produced a strong activation of both IFN- $\gamma$ (Fig. 6B) and IL-4 (Fig. 6C) promoter.

Proliferative effect of costimulation on proliferation response and IL2 production of $\mathrm{CD}^{+} \mathrm{T}$ cells to SEA and CHO-DR, CHODR/LFA-3 and CHO-DR/B7-1

Finally, we investigated the effect of B7-1 or LFA-3 costimulation on the induction of 

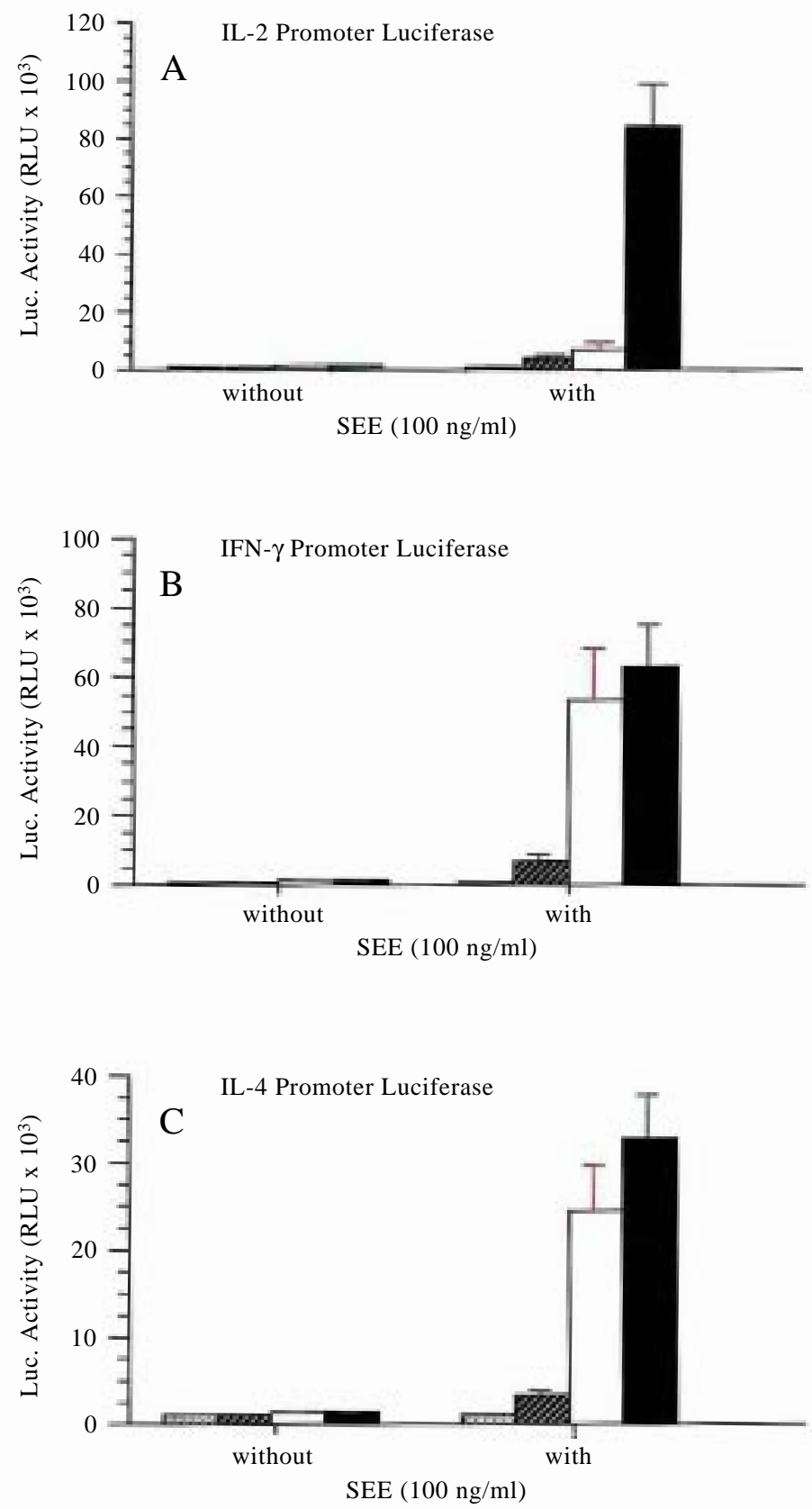

Figure 6

Comparison of the transcriptional regulation of the IL-2, IFN- $\gamma$ and IL-4 promoters in Jurkat T cells costimulated with CHO-DR, CHO-DR/LFA-3 and CHO-DR/B7-1 transfected cells. Jurkat T cells were transfected with the various luciferase promoter reporter genes and cultured in RPMI supplemented with $10 \%$ FCS. After $24 \mathrm{~h}$ the cells were treated with SEE and cultured for $8 \mathrm{~h}$ with the various CHO transfectants (1:10 ratio to $\mathrm{T}$ cells). Luciferase activity is expressed as RLU minus background units of buffer. The results shown are mean values from three similar experiments. Error bars indicate standard errors of the mean. 
proliferation and the production of IL-2, IFN- $\gamma$ and IL- 4 and correlated these results with the transcriptional activity of the MAP kinases ERK-2, JNK-1 and p38. T cell proliferation and IL- 2 , IFN- $\gamma$, and IL-4 production were measured in freshly prepared $\mathrm{CD}^{+} \mathrm{T}$ cells $\left(1 \times 10^{6} / \mathrm{ml}\right)$ cocultured with $10 \mathrm{ng} / \mathrm{ml} \mathrm{SEA}$ and with either CHO-DR, CHO-DR/LFA-3, or CHO-DR/ B 7-1 for $72 \mathrm{~h}$ at $37^{\circ} \mathrm{C}$. (Fig. 7). B 7-1 costimulation was required to induce large amounts of IL-2 (Fig. 7A) while both B7-1 and LFA-3 costimulation induced large amounts of IFN- $\gamma$ (Fig. 7B and C). However, only marginal levels of IL-4 were detected in supernatants of $\mathrm{T}$ cells costimulated with B7-1 and LFA-3. The proliferation activity that clearly correlated with the induction of IL- 2 and IFN- $\gamma$, also required B7-1 costimulation (Fig. 7D).

\section{DISCUSSION}

One of the most interesting signaling pathways involved in the activation of $\mathrm{T}$ cells is represented by the MAP kinase cascade. Signal one activates ERK-2 pathway and is involved in the survival of $\mathrm{T}$ cells (Minden et al., 1994; Nunes et al., 1996; Robinson et al., 1996). The second signal delivered via accessory molecules such as CD28 and CD2 led to the activation of the JNK and p38 pathways, responsible for induction of IL-2 receptor expression, IL-2 production and subsequent clonal expansion. Contrary to what has been previously proposed (Minden et al., 1994; $\mathrm{Su}$ et al., 1994; Robinson.et al., 1996) we show that the requirement for at least two signals for the efficient activation of $\mathrm{T}$ cells is not unique to JNK, as the ERK is also fully activated by TCR engagement and B71 or LFA-3 costimulation. We showed by kinase assays that $\mathrm{T}$ cells activated with SEE (signal one) alone substantially activated ERK, but not JNK or p38 pathways. On the other hand, $T$ cells activated with SEE and costimulated with CD28 or CD2 (signal two) showed a strong activation of all three pathways (ERK, JNK and p38). Our results also contrast with recent studies showing that the CD28 was not required for JNK activation in normal murine T cells (Rivas et al., 2001). In this study high concentrations of anti CD3 mAb alone were sufficient for ERK and JNK activation, even in the absence of anti CD28. This discrepancy may reflect differences in the use of superantigens SEE (signal one) and $\mathrm{CHO}$ transfectants expressing the ligands for CD28 and CD2 (signal two) in our studies, as compared with the use of anti-CD3 and anti-CD28 antibodies to induce a similar response or our use of a more physiological system for activation of $\mathrm{T}$ cells. The MAP kinases regulate the activity of $\mathrm{AP}-1$, a nuclear factor that plays a critical role in IL-2 gene transcription by binding to three different sites; NF-AT, Oct-1, and AP-1 itself (Durand et al., 1988; Granelli-Piperno et al., 1991). It has also been demonstrated that JNK activates the $c$-fos promoter through phosphorylation of TCF/Elk-1 (Gille et al., 1992) and that MEKK-1 kinase, an upstream kinase in the cascade of JNK, can also induce $c$-fos and Elk- 1 transcriptional activity in the presence of lower levels of ERK (Minden et al., 1994; 1995), suggesting the involvement of mechanisms other than the ERK signal in the activation of c-fos. In other systems, JNK, unlike ERK, is not activated by the phorbol ester alone, but rather requires the phorbol ester in combination with calcium ionophore (Nunes et al., 1996; Su et al., 1994; Robinson et al., 1996). Triggering of CD3 and CD28 also results in CsAsensitive activation of JNK, whereas each stimulus alone results in little or no activation.

However, the dramatic reduction in transcriptional IL-2 promoter activity observed with a luciferase reporter driven by IL-2 promoter containing a mutated CD28RE further underscores the functional importance of the B7-1 costimulation for IL-2 transcriptional activity. These observations, along with the EMSA experiments, indicate the presence of a functional CD28RE in the IL-2 promoter. It is worth commenting that LFA-3, in contrast with B7-1, cannot costimulate IL-2 production, but can costimulate cell proliferation. The results suggest that the 

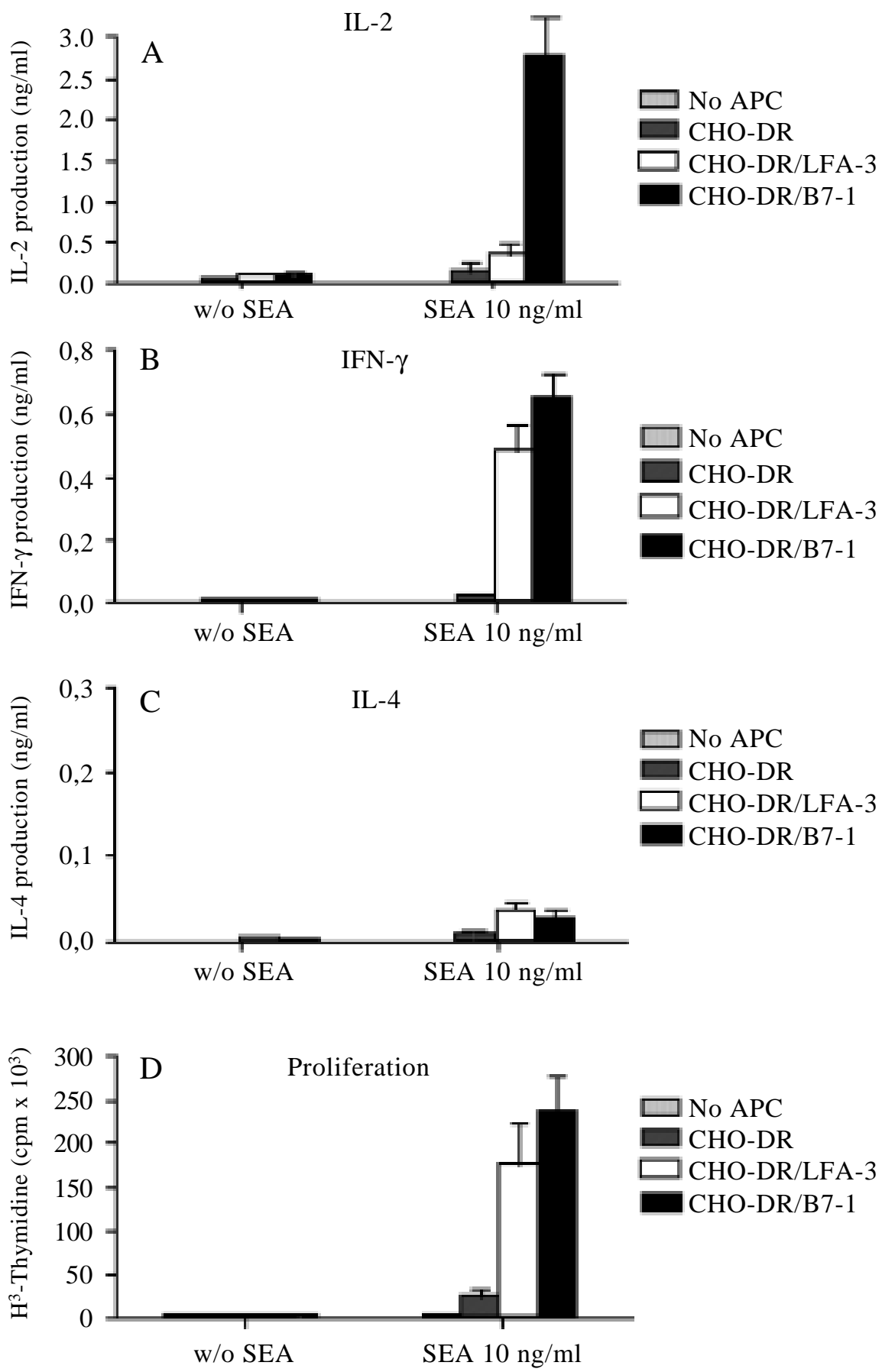

\section{Figure 7}

Costimulatory effect of LFA-3 and B7-1 in induction of IL-2 (A), IFN- $\gamma$ (B) and IL-4 (C) production and proliferation (D) of SEA primed T cells. In A, CD4 ${ }^{+} \mathrm{T}$ cells $\left(1 \times 10^{6} / \mathrm{ml}\right)$ were cultured for 3 days with RPMI supplemented with 10\% FBS, CHO-DR, CHO-DR/LFA-3 and CHO-DR/B7-1 $\left(0.1 \times 10^{6} / \mathrm{ml}\right)$ with or without SEA $(10 \mathrm{ng} / \mathrm{ml})$. In A, B, and C, supernatants from the same culture were collected on day 2 and assayed by ELISA for the production of the above mentioned citokines. In $\mathrm{D}$, the $\left[{ }^{3} \mathrm{H}\right] \mathrm{TdR}$ incorporation for proliferation was assessed the last $4 \mathrm{~h}$ of culture. Experiments were done at least three times and the most representative results were shown. Error bars indicate standard errors of the mean. 
differential effect of CD2/LFA-3 vs. CD28/ B7-1 on IL-2 regulation could be related to the difference of the ability of the two pathways to induce JNK activity. In this regard, other laboratories have reported that the activation of ERK, JNK and p38 is differentially sensitive to inhibitions of PI3K (Jascur et al., 1997). Both CD2 and CD28 are linked to the PI3K pathways, suggesting an alternative mechanism of activation of JNK and thus regulation of IL2 gene expression. The adhesion of the complex induced by the CD2/LFA-3 pathway was also inhibited by the loss of the functional CD28RE. However, earlier reports indicated a central role of CD28RE in CD28-costimulated $\mathrm{T}$ cells, although several studies suggested that the CD28RC was not exclusively seen in CD28stimulated T cells (Civil et al., 1992; Ghos et al, 1993). Using native B7-1 and LFA-3 ligands, we found that the CD28RC is detectable in EMSA by both B7-1 and LFA-3 costimulation. However, the B7-1 costimulation forms two distinct bands in the gel shift assay while the LFA-3 costimulation induces only the upper band. We speculate that the complex bound to the CD28RE, corresponding to the faster migrating band, may be involved in activation of IL2 promoter, as it is induced only by B7-1 and binds to CD28RE on its own as well as in combination with nuclear factors, such as AP-1. In our system, elevated ERK and JNK activities can be detected $1 \mathrm{~h}$ after SEE presentation to $\mathrm{T}$ cells, while p38 kinase induction was observed only after $2 \mathrm{~h}$, particularly in the presence of B7-1 costimulation. Thus, early activation of these kinases may be required for the activation of fos and jun genes, while kinase activity at later time-points may be important for activation of the transactivating capacity of the Fos and Jun proteins. Consequently, the TCR signal alone or together with LFA-3 costimulation does not affect JNK-1 and does not cause a synergistic effect in the activation of JNK1 , although its synergy is observed for the activation of p38 and ERK-2.

However, despite the fact that LFA-3 costimulation could increase the activity of ERK-2 and p38, only B7-1 costimulation correlates with high levels of IL-2 production, proliferation, transcriptional upregulation of IL- 2 and INF- $\gamma$ promoter activities, and the full induction of all three MAPKs. The high levels of proliferation observed in LFA-3 costimulated $\mathrm{T}$ cells imply that alternative pathways are involved in the activation of $T$ cells acting as an optional signal two to activated $\mathrm{T}$ cells for clonal expansion and citokine production. The signal delivered by CD28 pathway could account for a paracrine production of the IL-2 growth factor leading not only to clonal expansion of $\mathrm{CD}^{+}{ }^{+} \mathrm{T}$ cells, but also to the activation of other immunological cells such as B cells, CTL and NK cells. Our studies also clearly demonstrate a requirement for B7-1 costimulation for the full induction of transcriptional activity of the IL-2 and IFN- $\gamma$. The results suggest specificity of the JNK-1 kinase when B7-1 is applied as the second signal. The strong correlation between JNK-1 activation and transcriptional activity induced via the CD28/B7-1 pathway clearly supports a major role for this pathway in T survival, IL2 production, and proliferation, despite use of alternative pathways such as CD2/LFA-3 and LFA-1/ICAM-1 to deliver signal two. These observations suggest that the integration signals that lead to $\mathrm{T}$ cell activation and cytokine production may occur through the JNK/ERK pathway induced by B7-1 costimulation.

\section{ACKNOWLEDGEMENTS}

We would like to thank Dr. Roger J. Davis for providing us with the GST-c-Jun (1-79) and GST-ATF-2. This work was supported by the Swedish Institute, the Swedish Medical Research Council, and the Chilean National Science Foundation FONDECYT regular grant award 1020943.

\section{REFERENCES}

ANGEL P, IMAGAWA M, CHIU R, STEIN B, IMBRA RJ, RAHMSDORF HJ, JONAT C, HERRLICH P, KARIN $M$ (1987) Phorbol ester-inducible genes contain a common cis element recognized by a TPA-modulated trans-acting factor. Cell 49: 729-39 
ANGEL P, KARIN M (1991). The role of Jun, Fos and the AP-1 complex in cell proliferation and transformation. Biochim Biophys Acta 1072: 129-157

BIERER BE, HERRMANN S, BURAKOFF SJ (1988) Interaction of CD2 with its ligand, LFA-3 in human T cell proliferation. J Immunol 140: 3358-3362

BIERER BE, PETERSON A,GORGA JC, HERMANN SH, BURAKOFF SJ (1989) Synergistic T cell activation via the physiological ligand for $\mathrm{CD} 2$ and $\mathrm{T}$ cell receptor. J Exp Med 168: 1145-1153

BOULTON TG, NYE SH, ROBBINS DJ, IP NY, RADZIEJEWSKA E, MORGENBESSER SD, DEPINHO RA, PANAYOTATOS N, COBB MH, YANCOPOULOS GD (1991) ERKs: a family of protein-serine/threonine kinases that are activated and tyrosine phosphorylated in response to insulin and NGF. Cell 65: 663-75

CIVIL A, GEERTS M, AARDENL A, VERWEIJ CL (1992) Evidence for a role of CD28RE as a response element for distinct mitogenic $\mathrm{T}$ cell activation signal. Eur J Immunol 22: 3041-3051

DAVIS RJ (1994) MAPKs: new JNK expands the group. Trends Biochem Sci 19: 470-485

DURAND DB, SHAW JP, BUSH MR, REPLOGE RE, BELAGAJE R, CRABTREE GR (1988) Characterization of antigen receptor response elements within the interlekin-2 enhancer. Mol Cell Biol 8: 1715-1726

FAROUDI M, ZARU R, FAVIER B, VALITUTTI S (2002) New insights to the functional role of the $T$ cellantigen presenting cell immunological synapse. Biol Res 35: 133-137

FRASER JD, IRVING BA, CRABTREE GR, WEISS A (1991) Regulation of interleukin-2 gene enhancer activity by the $\mathrm{T}$ cell accessory molecule CD28. Science 251: 313-316

FRASER JD, WEISS A (1992) Regulation of T-cell lymphokine gene transcription by the accessory molecule CD28. Mol Cell Biol 12: 4357-4363

FREEMAN GJ, FREEDMAN AS, SEGIL JM., LEE G, WHITMAN JF, NADLER LM (1989) B7, a new member of the Ig superfamily with unique expression on activated and neoplastic B cells. J Immunol 143: 2714-2726

GHOS P, TAN T, RICE NR, SICA A, YOUNG HA (1993) The interleukin 2 CD28-responsive complex contains at least three members of the $\kappa \mathrm{B}$ family, c-Rel, p50 and p65. Proc Natl Acad Sci USA 90: 1696-1700

GILLE H, SHARROCKS A, SHAW P (1992) Phosphorylation of p62TCF by MAP kinase stimulates ternary complex formation at c-Fos promoter. Nature 358: 414-417

GRANELLI-PIPERNO A, NOLAN P (1991) Nuclear transcription factors that bind to elements of the IL-2 promoter. Induction requirements in primary human $\mathrm{T}$ cells. J Immunol 147: 2734-2739

GUPTA S, CAMPBEL D, DERIJARD B, DAVIS RJ (1995) Transcription factor ATF-2 by the JNK signal transduction pathway. Sci 267:389-393

HIBI M, LIN A, SMEAL T, MINDEN A, KARIN M. (1993) Identification of an oncoprotein- and UVresponsive protein kinase that binds and potentiates the c-Jun activation domain. Genes Dev 11: 2135-2148

JAIN J, MCCAFFRE PG, VALGE-ARCHER VE, RAO A. (1992a) Nuclear factor of activated T cells contains Fos and Jun. Nature 356: 801-804

JAIN J, VALGE-ARCHER VE, RAO A (1992b) Analysis of the AP-1 sites in the IL-2 promoter. J Immunol 148: 1240-1250

JANEWAY CA, GOLSTEIN M (1993) Lymphocyte activation and effector functions: the role of cell surface molecules. Curr Opin Immunol 5: 313-323
JASCUR T, GILMAN J, MUSTELIN T (1997) Involvement of phosphatidylinositol 3-kinase in NF-AT activation in T cells. J Biol Chem 272: 14483-14488

KABELIT D (1990) Do CD2 and CD3 TCR T cell activation pathways function independently? Immunol Today 11: 44-47

KARIN M (1995) The regulation of AP-1 activity by mitogen-activated protein kinases. J Biol Chem 270:16483-16486

LEE W, MITCHELL P, TJIAN R (1987) Purified transcription factor AP-1 interacts with TPA-inducible enhancer elements. Cell 49: 741-52

LEIVA-SALCEDO E, PEREZ V, ACUNA-CASTILLO C, WALTER R, SIERRA F (2002) T-kininogen inhibits kinin-mediated activation of ERK in endothelial cells. Biol Res 35: 287-294

LENSCHOW DJ, WALUNAS TL, BLUESTONES JA (1996) CD28/B7 system of T cell costimulation. Clin Immunol Immunophatol 14: 233-258

LINSLEY PS, CLARK EA, LEDBETTER JA (1990) T-cell antigen CD28 mediates adhesion with B cells by interacting with activation antigen B7/BB1. Proc Natl Acad Sci USA 87: 5031-5050

LINSLEY PS, BRADY W, GROSMAIRE L, ARUFFO A, DAMLE NK, LEDBETTER JA (1991) Binding of the $B$ cell activation antigen $B 7$ to $C D 28$ costimulates $T$ cell proliferation and interleukin 2 mRNA accumulation. J Exp Med 173: 721-730

MATTILA PS, ULLMAN KS, FIERING S, EMMEL EA, MCCUTCHEON M, CRABTREE GR, HERZENBERG LA (1990) The actions of cyclosporin A and FK506 suggest a novel step in the activation of tymphocytes. EMBO J 9: 4425-4433

MINDEN A, LIN A, MCMAHON M, LANGE-CARTER C, DERIJARD B, DAVIS RJ, JOHNSON GL, KARIN M. (1994). Differential activation of ERK and JNK mitogen activated protein kinases by raf-1 and MEKK. Sci 266: 1719-1723

MINDEN A, LIN FX, CLARET A, KARIN M (1995) Selective activation of the JNK signaling cascade and c-Jun transcriptional activity by the small GTPases Rac and Cdc42Hs. Cell 81: 1147-1157

NEBREDA AR (1994) Inactivation of MAP kinases. Trends Biochem Sci 19:1-2

NUNES JA, BATTIFORA M, WOODGETT JR, TRUNEH A, OLIVE D, CANTRELL DA (1996) CD28 signal transduction pathways. A comparison of B7-1 and B7-2 regulation of the map kinases: ERK-2 and Jun kinases. Mol Immunol 33: 63-70

PARRA E, WINGREN AG, HEDLUND G, SJOGREN HO, KALLAND T, SANSOM D, DOHLSTEN M. (1993) Human Naive and Memory T-helper cells display distinct adhesion proprieties to ICAM-1, LFA-3 and B7 molecules. Scand J Immunol 38: 508-516

PARRA E, WINGREN A, HEDLUND G, BIARKLUND O, LEANDESON T, SJOGREN HO, KALLAND T, SANSOM D, DOLHLSTEN M (1994) Costimulation of human $\mathrm{CD} 4^{+} \mathrm{T}$ cells with $\mathrm{B} 7$ and lymphocyte functionassociated antigen- 3 results in distinct cell activation profiles. J Immunol 153: 2479-2489

PARRA E, VARGA M, SIGVARDSSON M, HEDLUND G, KALLAND T, LEANDERSON T, SJOGREN HO, DOHLSTEN M (1995) Costimulation of $\mathrm{CD}^{+} \mathrm{T}$ cells with B7-1 and LFA-3 induce distinct effect on AP-1 and NF- $\kappa$ B. J Immunol 155: 1132-1141

PARRA E, VARGA M, HEDLUND G, KALLAND T, DOHLSTEN M (1997) Costimulation by B7-1 and LFA-3 target distinct nuclear factors that bind to the Interleukin2 promoter: B7-1 negatively regulates LFA-3 induced NF-AT DNA binding. Mol Cell Biol 17: 1314-1325 
PARRA E (2002) The role of the B7-1/2, LFA-3 and ICAM-1 costimulatory molecules in the modulation of $\mathrm{T}$ cell responses. Inmunologia 21:102-114

RABB M, CAI Y-C, BUNNEL SC, HEYECK SD, BERG LJ, RUDD CE (1995) P56Lck and p59Fyn regulate CD28 binding to phosphatidylinositol-3-kinase, growth factor receptor-bound protein GRB-2, and $\mathrm{T}$ cell-specific protein-tyrosine kinase ITK: implications for T cell costimulation. Proc Natl Acad Sci USA 92: 8891-8895

RAHMSDORF HJ, HERRLICH P (1990) Regulation of gene expression by tumor promoters. Pharmacol Ther 48: $157-188$

RIVAS F, OHERRIN S, GAJEWSKI. T (2001) CD28 is not required for c-jun $\mathrm{N}$-terminal kinase activation in $\mathrm{T}$ cells. J Immunol 167:3132-3128

ROBINSON MJ, COBB MI (1996) Mitogen-activated protein kinase pathway. Curr Opin Cell Biol 9:180-196

SCHNEIDER H, CAI Y-C, PRASAD KVS, SHOELSON SE, RUDD CE (1995) T cell antigen CD28 binds to the GR/SOS complex, regulators of $\mathrm{p} 21^{\text {ras }}$. Eur J Immunol 25: $1044-1050$

SCHWARTZ RH (1992) Costimulation of T lymphocytes: The role of CD28, CTLA-4, and B7-BB1 in interleukin-2 production and immunotherapy. Cell 71: 1065-1068

SHAW JP, UTZ PJ, DURAND DB, TOOLE JJ, EMMEL EA, CRABTREE GR (1988) Identification of a putative regulator of early $\mathrm{T}$ cell activation genes. Science 241: 202-205
SPRINGER TA, DUSTIN ML, KISHIMOTO TK, MARLIN SD (1987) The lymphocyte function-associated LFA-1, CD2 and LFA-3 molecules: cell adhesion receptors of the immune system. Annu Rev Immunol 5: 223-252

SPRINGER TA (1990) Adhesion receptors of the immune system. Nature 346: 425-433

SU B, JACINTO E, HIBI M, KALLUNKI T, KARIN M, BENNERIAH Y (1994) JNK is involved in signal integration during costimulation of T lymphocytes. Cell 77: 727-736

SUNDSTEDT A, HOIDEN I, ROSENDAHL A, KALLAND T, VAN ROOIJEN N, DOHLSTEN M (1997) Immunoregulatory role of IL-10 during superantigeninduced hyporesponsiveness in vivo. 158: 180-186

STEAL T, MERCOLA DA, BIRRE M, KARRIN (1991) Phosphorylation of c-Jun serines 63 and 73 is required for oncogenic and transcriptional cooperation with Ha-Ras. Nature 35: 9-12

VAN SEVENTER GA, SHIMIZU Y, SHAW S (1991) Roles of multiple accessory molecules in T-cell activation. Curr Opin Immunol 3: 294-303

WILLIAMS TM, MOOLTEN DM, MAKNI H, KIM HW, KANT JK, KAMOUN M (1992) CD28-stimulated IL-2 gene expression in Jurkat $\mathrm{T}$ cells occurs in part transcriptionally and is cyclosporine A sensitive. J Exp Med 145: 2609-2622

ZHANG J, SALOJIN KV, GAO JX, CAMERON MJ, BERGEROT I, DELOVITCH TL (1999) P38 mitogenactivated protein kinase mediates signal integration of TCR/CD28 costimulation in primary murine T cells. J Immunol 162: 3819-3829 